\title{
Video-assisted thoracic surgery in lung cancer: Lung resection and mediastinal lymph node staging
}

\author{
Daniel G. Cuadrado • Eric L. Grogan
}

Published online: 15 February 2012

(C) Springer Science+Business Media, LLC 2012

\begin{abstract}
Despite our ever-increasing ability to target the molecular and genetic pathways responsible for non-small cell lung cancer (NSCLC), anatomic surgical resection remains the mainstay of treatment for those without evidence of systemic disease. Although these procedures can be performed with relatively low mortality, the age and coexisting conditions of the population lends itself to a myriad of potential complications. Minimally invasive surgical approaches to the treatment of lung cancer hold the potential to offer curative resection to a much broader group of patients without compromising oncologic principles.
\end{abstract}

Keywords Non-small cell lung cancer · VATS · Lobectomy · Minimally invasive surgery

D. G. Cuadrado • E. L. Grogan

Tennessee Valley Health Care System,

Nashville Veterans VA Medical Center,

Nashville, TN, USA

D. G. Cuadrado

Department of Cardiac Surgery,

Vanderbilt University Medical Center,

Nashville, TN, USA

\section{E. L. Grogan}

Department of Thoracic Surgery,

Vanderbilt University Medical Center,

Nashville, TN, USA

\section{E. L. Grogan $(\bowtie)$}

Department of Thoracic Surgery,

609 Oxford House, 131321 st Avenue,

South Nashville, TN 37232, USA

e-mail: eric.grogan@vanderbilt.edu

\section{Introduction}

Lung cancer remains one of the leading causes of cancer deaths in the United States accounting for 219,450 new cases and 159,390 deaths in 2009 [1]. NSCLC accounts for $80 \%$ of all cases. Although rates of heavy smoking have declined significantly since the 1964 Surgeon General's report, there are currently 94 million current or former smokers at risk for the disease [2]. More than half of NSCLC patients are older than 65 years at the time of diagnosis, with $30 \%$ older than 70 years [3-5]. Based on recent reports, we can expect increasing utilization of lowdose computerized tomographic screening with the hope of detecting earlier stage tumors [6]. Despite recent advances in multimodality therapies, anatomic surgical resection remains the standard of care for early-stage disease.

The 1995 publication from the Lung Cancer Study Group's (LCSG) prospective randomized trial of lobectomy versus limited resection for stage IA NSCLC reinforced the need for formal lobar resection in early-stage disease [7]. Sublobar resection was found to have increased risk of local/ regional recurrence and higher 5-year mortality, with no evidence of preserved pulmonary function $[7,8]$. The standard treatment therefore became rib-spreading thoracotomy with direct vision and formal anatomic resection. Although large series have demonstrated low mortality rates, perioperative morbidity rates have been as high as $32 \%$ [9-11]. It was in this environment with an ever aging and more comorbid population, that minimally invasive approach to resection was developed.

Hans Christian Jacobaeus described the first thoracoscopic procedure in 1910 [12]. The first reports of videoassisted thoracic surgery (VATS) pulmonary lobectomy were published in the early 1990s [13-15]. The theoretical advantages were less surgical trauma, improvements in 
post-operative pain, enhanced recovery, and less overall morbidity. Despite a growing body of evidence to support these advantages, $70 \%$ of lobectomies are still performed via thoracotomy [11]. As is the case with all minimally invasive surgical procedures, an initial learning curve exists. An en bloc resection of the target lobe must be performed using standard oncologic resection techniques isolating and separately dividing the arteries, veins, and bronchus and performing a mediastinal lymph node dissection for staging. This review will examine the evidence that VATS lobectomy decreases surgical morbidity without compromising oncologic principles for patients with early-stage NSCLC as well as the ever-expanding indications.

Minimally invasive (VATS) lobectomy definition

Although a full discussion of the techniques of VATS lobectomy is beyond the scope of this review, some critical elements exist. One key principle for the reduction of surgical trauma is the elimination of rib-spreading through the use of the thoracoscope for visualization. Although the original technical descriptions did not use rib-spreading, a study by Yim et al. [16] surveyed 33 thoracic surgeons worldwide and found that $70 \%$ of respondents utilized a rib spreader at one point during the procedure. The location and number of incisions was found to vary as well with $48 \%$ reporting use of a utility incision greater than $6 \mathrm{~cm}$ in length. The Cancer and Leukemia Group B study (CALGB 39802), which examined feasibility of VATS lobectomy for tumors $\leq$ $3 \mathrm{~cm}$, established a unified technique and helped standardize the approach for VATS lobectomy [17•]. VATS lobectomy was defined by a $4-8 \mathrm{~cm}$ access incision with an additional two port incisions. Furthermore, videoscopic guidance was mandated and hilar dissection was performed without rib spreading. This study established the feasibility of VATS lobectomy in 127 patients with a mortality of $2.4 \%$ and severe complication rate of $7.4 \%$. Long-term survival in this cohort was equivalent to historical controls.

Patient selection

Based on the National Comprehensive Cancer Network (NCCN) guidelines for patients with the pathologic diagnosis of NSCLC all patients should have a complete H\&P (to include performance status), pathologic review, CT scan of the chest through the adrenals, baseline labs, smoking cessation counseling, and pulmonary function testing. Patients who are surgical candidates require clinical staging of the mediastinum to rule out metastatic disease. F18fluorodeoxyglucose positron emission tomography (FDGPET) is typically performed and surgical staging of the mediastinum by either endobronchial ultrasound (EBUS) or mediastinoscopy (CME) is necessary to determine the status of lymph nodes that are either FDG avid or $>1 \mathrm{~cm}$. Surgical staging of the mediastinum should be considered for any patient with $\mathrm{T} 2$ status, suspicion of $\mathrm{N} 1$ or N2 disease on CT scan, or clinical findings suggestive of advanced disease [18].

Video-assisted thoracic surgery lobectomy is an acceptable approach in patients without anatomic or surgical contraindications. The absolute contraindications for VATS lobectomy are inability to tolerate single lung ventilation and pleural symphysis. Large tumors, $>4 \mathrm{~cm}$, are a relative contraindication given that specimen retrieval usually requires some degree of rib spreading that may negate some of the benefits of VATS. Special patient populations in which VATS lobectomy has shown to have additional benefits are listed in Table 1.

For patients at highest risk for perioperative complications, VATS lobectomy has been shown to have advantages in selected series (Table 1). In patients with high preoperative comorbidities, Whitson et al. [19] reported fewer complications with equivalent OR times, blood loss, hospital length of stay, and survival rate. In patients in the seventh decade of life, a matched case-controlled study demonstrated patients undergoing VATS lobe had fewer severe complications and a shorter length of stay than their thoracotomy counterparts [20]. In this same age group, Demmy et al. [21] showed that patients undergoing open thoracotomy were more likely to be discharged to a skilled nursing facility or require home assistance than those undergoing VATS lobectomy. Similar results have been seen in smaller series of patients over the age of 80 [22, 23]. Studies comparing pulmonary function of VATS versus open lobectomy consistently demonstrate improved pulmonary function in patients undergoing VATS [24-28]. Nagahiro [25] found a quicker recovery in forced vital capacity (FVC) and forced expiratory volume in $1 \mathrm{~s}$ (FEV1) in the first 2 weeks following VATS lobectomy. Petersen et al. [29] examined the chemotherapy compliance between 100 patients undergoing VATS and open lobectomy. They found that patients undergoing VATS lobectomy received $75 \%$ or more of their

Table 1 Populations with defined benefit of VATS lobectomy

\begin{tabular}{ll}
\hline Population & Reference(s) \\
\hline Stage IA NSCLC & {$[17 \bullet, 19,30,31 \bullet \bullet$} \\
& $33,39,43,47]$ \\
Elderly (age $>$ & {$[20,23,46,56]$} \\
70 years) & {$[24-26]$} \\
$\begin{array}{l}\text { Poor pulmonary } \\
\text { function* }\end{array}$ & {$[19,36]$} \\
High comorbidity & {$[29]$} \\
Planned adjuvant & \\
therapy & \\
\hline
\end{tabular}

*Defined as FEV $1<0.8 \mathrm{~L}$. 
planned adjuvant regimen compared to only $40 \%$ in the thoracotomy group. In summary, VATS lobectomy has been shown to improve outcomes in patients with high comorbidities in highly selected series.

\section{Oncologic results}

In terms of recurrence, Sugi et al. [30] demonstrated in a randomized control trial that local recurrence rates were similar between VATS and thoracotomy lobectomy. The most recent meta-analysis pooled six trials that examined local recurrence and found similarly that there was no statistically significant difference (relative risk $[R R]=0.64$; $95 \%$ confidence interval $[\mathrm{CI}], 0.30$ to $1.35 ; P=0.24$ ) $[31 \bullet \cdot]$. This same analysis found that systemic recurrence was lower when comparing VATS to open lobectomy $(\mathrm{RR}=$ $0.72 ; 95 \% \mathrm{CI}, 0.34$ to $0.95 ; P=0.04)$. With respect to 5 -year survival, of the seven studies pooled in the analysis, VATS had an improved overall 5-year survival compared to open lobectomy $(\mathrm{RR}=0.72 ; 95 \% \mathrm{CI}, 0.45$ to 0.97$)$.

Mediastinal lymph node staging

An early concern raised by opponents of VATS lobectomy was the adequacy of lymph node dissection. In order to examine the adequacy of lymphadenectomy, Sagawa et al. [32] performed VATS lobectomy with lymph node dissection followed by second surgeon performing a thoracotomy to access the number of residual lymph nodes. The authors found that with right and left sided VATS lobectomies, the rates of appropriate lymph node dissection were $97 \%$ and $98 \%$, respectively. Similar results were seen in the American College of Surgeons Oncology Group (ACOSOG) Z0030 national cooperative trial, in which the number of lymph node stations sampled and lymph nodes removed were similar between VATS and open lobectomy [33]. Additional trials by Kirby [34] (VATS vs muscle-sparing thoracotomy) and Watanabe [35] (VATS+MLND vs open+MLND) also demonstrated similar numbers of lymph nodes dissected for each group. Furthermore, a large-scale analysis of the NCCN database has shown that there is no difference in the number of lymph node stations sampled by either the VATS or open approach [36].

Performance of a complete mediastinal lymphadenectomy (MLND) at the time of pulmonary resection is controversial. Passlick et al. [37] have demonstrated an increased long-term survival in patients with MLND in which immunohistochemically detected lymph nodes were found. The American College of Surgeons Oncology Study Groups (ACOSOG) trial Z0030, which contained both VATS and open lobectomy, demonstrated that lobectomy+MLND can be performed safely with minimal increase in morbidity (38\%) and mortality (1.4\%) [33]. Long-term data from this cohort should help to answer the question as to the survival impact of MLND versus nodal sampling.

\section{VATS lobectomy mortality}

Current evidence suggests that VATS lobectomy can be performed for early-stage NSCLC with mortality results that are similar to the open approach $[31 \bullet \cdot]$. The largest reported series of VATS lobectomy by McKenna et al. includes 1048 resections for primary lung cancer with a mortality rate of $0.8 \%$ respectively [10], [38•]. Other large series report operative mortality rates from $0 \%$ to $2 \%[39,40]$. A secondary analysis of the ACOSOG Z0030 was performed comparing VATS to open lobectomy with similar operative mortality rates ( $0 \%$ and $1.6 \%$ respectively, $P=1.0$ ) [39]. Figures 1 and 2 demonstrate the pooled analysis of the morbidity and mortality of VATS versus open lobectomy.

\section{VATS lobectomy morbidity}

As with open lobectomy, the most common complications seen following VATS lobectomy include arrhythmias, prolonged air leak, and pneumonia. In most series, atrial dysrhythmias remain the most common complication. Major complications such as pneumothorax, respiratory failure, and myocardial infarctions occur in less than $1 \%$ of cases. In the meta-analysis by Yan et al. [31••], no statistical differences with respect to prolonged air leaks, arrhythmias, or pneumonias were found when comparing VATS to

\begin{tabular}{|c|c|c|c|c|}
\hline \multirow[t]{2}{*}{ Event } & \multicolumn{2}{|r|}{ RR (95\% Cl) } & $\begin{array}{l}\text { VATS events/ } \\
\text { VATS no events }\end{array}$ & $\begin{array}{l}\text { Open events/ } \\
\text { open no events }\end{array}$ \\
\hline & Favors VATS & Favors Open & & \\
\hline Pneumonia & & $0.24(0.10,0.57)$ & $6 / 266$ & $25 / 263$ \\
\hline Arrythmia & & $0.92(0.62,1.35)$ & $47 / 491$ & $46 / 441$ \\
\hline Prolonged air leak & $\longrightarrow$ & $0.81(0.48,1.39)$ & $23 / 504$ & $28 / 500$ \\
\hline & $\begin{array}{ll} & \\
& \end{array}$ & 2 & & \\
\hline
\end{tabular}

Fig. 1 Comparison of morbidity, VATS versus open lobectomy 


\begin{tabular}{|c|c|c|c|c|c|}
\hline \multirow[t]{2}{*}{ Event } & \multicolumn{3}{|c|}{$\operatorname{RR}(95 \% \mathrm{Cl})$} & $\begin{array}{l}\text { VATS events/ } \\
\text { VATS no events }\end{array}$ & \multirow[t]{2}{*}{$\begin{array}{l}\text { Open events/ } \\
\text { open no events }\end{array}$} \\
\hline & Favors VATS & Favors & pen & & \\
\hline Mortality & & & $0.54(0.13,2.27)$ & $3 / 749$ & $5 / 679$ \\
\hline Local recurrence & $\bullet$ & & $0.54(0.31,0.93)$ & $20 / 457$ & $32 / 395$ \\
\hline Systemic recurrence & $\longrightarrow$ & & $0.56(0.34,0.92)$ & $24 / 376$ & $36 / 316$ \\
\hline All-cause mortality & $\longrightarrow$ & & $0.55(0.38,0.79)$ & $44 / 541$ & $65 / 439$ \\
\hline & .5 & 2 & & & \\
\hline
\end{tabular}

Fig. 2 Comparison of mortality and survival, VATS versus open lobectomy

thoracotomy. The rates of surgical conversion to thoracotomy ranged from $0 \%$ to $15.7 \%$. VATS lobectomy has been shown to reduce intraoperative blood loss and chest drain duration [41-43]. Several series have demonstrated a decreased hospital length of stay when compared to standard thoracotomy. In their large single-institution series, McKenna et al. [38•] reported morbidity rates of $15.3 \%$.

\section{Arrhythmias}

Post-operative arrhythmias, particularly atrial fibrillation, are frequent complications of pulmonary resection often resulting in a prolonged patient stay. The pathogenesis of atrial fibrillation in the post-operative period is multifactorial in nature. Early proponents of minimally invasive pulmonary resection proposed that decreasing the surgical incisional trauma might lead to a decrease in atrial arrhythmias. This, however, has not proved to be the case reliably in all series [19, 27, 43-48]. The meta-analysis by Yan et al. [31••] found that the rate of atrial arrhythmias in VATS lobectomy was similar to that observed in the open procedure (RR, 0.99; 95\% CI, 0.52-1.91; $P=0.98$ ). This suggests that the surgical incision is not the primary actor and that parenchymal and vascular dissection, neurohormonal mechanism, and denervation play a larger role in the arrhythmogenesis.

\section{Chest tube drainage and air leaks}

Regardless of the technique utilized, $30 \%-50 \%$ of patients have evidence of an air leak following pulmonary resection $[49,50]$. Risk factors for development of a postoperative air leak are reduced pulmonary function, fragile lung parenchyma, pleural adhesions, and the use of steroids [51]. Prolonged air leak is typically defined as an air leak that persists $\geq 5$ days or one that increases the hospital length of stay. Prolonged air leaks increase the risks of empyema, impact hospitalization costs, and may increase the rate of cardiopulmonary complications. In the meta-analysis by Yan et al. [31••], 10 studies were examined which compared the incidence of prolonged post-operative air leak [19,
27, 41, 43, 46-48, 52-54]. There was no difference seen between VATS and open lobectomy $(\mathrm{RR}=0.90$; 95\% CI, 0.52-1.55; $P=0.71)$ [31••].

Chest drain duration following VATS lobectomy is more difficult to determine. Across the multiple randomized and nonrandomized trials, no clear consensus for the timing of chest drain removal exists. Although some trials support shorter chest drain time with VATS lobectomy versus open $[42,43]$, others show no difference [19, 25, 27, 45, 52]. A secondary analysis of the ACOSOG Z0030 showed fewer instances of chest drainage over 7 days $(1.5 \%$ vs $10.8 \%, P=$ 0.29 ) and the median total chest tube drainage was lower in the VATS group [39].

Postoperative pain and recovery

The postoperative recovery appears to be better for the VATS approach when compared to open lobectomy [55]. Postoperative pain as evidenced by visual pain scales, narcotic requirement, and sleep disturbances is less following VATS lobectomy [56]. Narcotic pain medication utilization has been shown to be significantly reduced in the early postoperative period (POD 1-7) [56]. Likewise, pain medication requirements have been seen to be lower at 3 weeks. Longer-term reductions in pain and severe pain have been found to be reduced at 3 months and persist at 1 year [42]. Of note, not all studies were consistent with the non-rib spreading technique of VATS lobectomy.

The quality of life following VATS lobectomy has also been examined $[57,58]$. A prospective study of 100 patients undergoing surgery for lung cancer looked at quality-of-life questionnaires done preoperatively, and at 1-, 3-, 6-, and 12-month intervals [57]. Improved physical function was seen up to 12 months in patients who underwent VATS compared to open lobectomy. Additionally, pain favored VATS over thoracotomy even up to 12 months [41].

\section{Learning curve}

The feasibility of VATS lobectomy has been well established; the procedure has proven to be safe and can be 
performed without compromising oncologic efficacy. Yet in the United States, only $30 \%$ of lobectomies are performed VATS [11]. One factor for this low penetrance into general thoracic practice is the technical complexity of the operation [59]. In 2006, Ferguson [60] compared the results of a single self-taught consultant surgeon to four surgical trainees. The effect of experience was demonstrated by the reduction in operative times and blood loss for the consultant over time. Similarly, for trainees, VATS lobectomy had no adverse impact on mortality, blood loss, or hospital length or stay.

Training in VATS lobectomy is offered in most US cardiothoracic training programs today. There are also 6-month to 12-month fellowships that specialize in advanced VATS procedures. For practicing thoracic surgeons, there are technical courses offered by professional societies and other practicing surgeons. Most surgeons feel that it takes about 50 VATS lobectomies to be comfortable with the procedure [44]. Specific technical concerns do exist. Bleeding from the pulmonary artery can occur more easily and be more difficult to control [61]; however, the rate of major bleeding is less than $1 \%$.

Conversion rates from VATS to open lobectomy range from $0 \%$ to $15.7 \%$ [55]. Reasons for conversion include technical factors such as failure to progress and uncontrollable bleeding, which tend to decrease with experience. However, anatomic factors such as extent of tumor, mediastinal involvement, calcified lymph nodes, and complete fusion of the fissures do persist.

\section{Immunomodulation}

The biologic impact of VATS versus open lobectomy has been examined in multiple in vivo trials [53, 62-64]. VATS lobectomy was associated with reduced impairment of cellmediated immunity as demonstrated by improved postoperative CD4 counts, natural killer cell function, and improved cellular cytotoxicity $[62,64]$. Likewise, smaller increases in acute phase reactants (interleukin 6, C-reactive protein) were seen with VATS when compared to thoracotomy [53, 65]. Although these findings may explain the improved recovery seen with VATS lobectomy, whether this translates into long-term survival is unknown.

\section{Chest wall involvement and other advanced resections}

The effects of avoid rib spreading with thoracotomy is touted as one of the main advantages to the VATS approach. Chest wall involvement has classically been felt to be a contraindication to VATS, given the need for en bloc resection with the involved portions of rib. There is, however, evidence that each intercostal nerve that is protected from rib spreading improves postoperative pain. By removing only the involved ribs and limiting trauma from retraction of the chest wall some surgeons feel there may be a functional recovery advantage for the patient. Yendamuri et al. [66] reported their experience with three patients who underwent thoracoscopic lobectomy with en bloc chest wall resection. Two patients had undergone neoadjuvant therapy prior to resection and one required a reexploration for a chest wall hematoma. All patients were off of narcotic pain medications by 3 weeks postoperatively. This procedure is not appropriate for patients requiring large chest wall resection ( $>4$ ribs) or post-scapular resection requiring reconstruction.

Bronchoplastic (sleeve) procedures for central lung cancers are routinely performed for parenchymal preserving curative resection [67]. Small series of VATS bronchoplastic resections have been published [68]. Authors describe the multiple technical challenges inherent in this approach. Currently it is limited to hilar tumors without evidence of vascular invasion. Additionally, VATS has been extended to pneumonectomy as well as sublobar resection $[69,70]$.

\section{Robotic lobectomy}

Experience with utilizing robotic technology for lobectomy is still evolving and the data are not as robust as for the VATS approach. Proponents for developing this procedure emphasize that the three-dimensional visualization, improved degrees of freedom of the instruments, and ease of fine dissection facilitate the performance of VATS lobectomy. At this point, the published experience is limited to small series [71, 72].

As with all robotic procedures, a steep learning curve exists. Gharagozloo et al. [72] published their experience with 100 robot-assisted lobectomies. The technique included utilizing the robot for the mediastinal, subcarinal, and hilar dissection followed by conversion to VATS lobectomy through an access incision for division of vascular, parenchymal, and bronchial structures. In their experience the morbidity and mortality were $21 \%$ and $3 \%$, respectively.

Some notable disadvantages to robotic lobectomy are the difficulty in lung manipulation, insertion of staplers, and requirement for a skilled assistant as the surgeon is remote from the operative field. However, there have been over 1500 robotic surgical systems sold in the United States, and as more thoracic surgeons begin adopting robotics for mediastinal procedures such as thymectomy, we can expect this field to continue to expand [73].

\section{Conclusions}

Lung cancer remains one of the predominant causes of cancer death in the United States today. With the emerging evidence for low-dose CT screening, and the large 
population of current and former smokers at risk, we will hopefully begin seeing larger numbers of patients with early-stage disease. Although no large randomized controlled trial exists, there is a growing body of evidence to support that video-assisted thoracic surgery lobectomy is oncologically equivalent to thoracotomy, has similar mortality rates, and may be superior with respect to surgical morbidity. It may be advantageous in elderly and high-risk populations but this is reported only in highly selected series. It is important to recognize that, as with all highly technical procedures, a learning curve exists and a certain level of expertise is necessary to obtain the results equal to those reported from high-volume centers of excellence.

Disclosure No potential conflicts of interest relevant to this article were reported.

\section{References}

Papers of particular interest, published recently, have been highlighted as:

- Of importance

-. Of major importance

1. Jemal A, Siegel R, Ward E, et al. Cancer statistics, 2009. CA Cancer J Clin. 2009;59:225-49.

2. Pierce JP, Messer K, White MM, et al. Prevalence of Heavy Smoking in California and the United States, 1965-2007. JAMA: The Journal of the American Medical Association. 2011;305:1106-12.

3. Gridelli C. Chemotherapy of non-small cell lung cancer in the elderly. Lung Cancer. 2002;38:67-70.

4. Gridelli C, Perrone F, Monfardini S: Lung cancer in the elderly. European journal of cancer (Oxford, England: 1990) 1997;33:2313-4.

5. Yancik R, Ries LAG. AGING AND CANCER IN AMERICA: Demographic and Epidemiologic Perspectives. Hematology/Oncology Clinics of North America. 2000;14:17-23.

6. Reduced Lung-Cancer Mortality with Low-Dose Computed Tomographic Screening. New England Journal of Medicine 2011;365:395-409.

7. Ginsberg RJ, Rubinstein LV. Randomized trial of lobectomy versus limited resection for T1 N0 non-small cell lung cancer. Lung Cancer Study Group. Ann Thorac Surg. 1995;60:615-22. discussion $22-3$

8. Lederle FA, Rubinstein LV, Ginsberg RJ. Lobectomy Versus Limited Resection in T1 N0 Lung Cancer. Ann Thorac Surg. 1996;62:1249-50.

9. Ginsberg R, Hill L, Eagan R, et al. Modern 30-day operative mortality for surgical resections in lung cancer. J Thorac Cardiovasc Surg. 1983;86:654-8.

10. Damhuis R, Schutte P. Resection rates and postoperative mortality in 7,899 patients with lung cancer. Eur Respir J. 1996;9:7-10.

11. Boffa DJ, Allen MS, Grab JD, et al. Data from The Society of Thoracic Surgeons General Thoracic Surgery database: The surgical management of primary lung tumors. J Thorac Cardiovasc Surg. 2008; 135:247-54.

12. Jacobaeus H. Ueber die moglichkeit die zystoskopie bei untersuchung seroser hohlungen anzuqenden. Munch Med Wochenschr. 1910;57:2090-2.
13. Kirby TJ, Mack MJ, Landreneau RJ, et al. Initial experience with video-assisted thoracoscopic lobectomy. Ann Thorac Surg. 1993;56:1248-52. discussion 52-3.

14. Walker WS, Carnochan FM, Pugh GC. Thoracoscopic pulmonary lobectomy. Early operative experience and preliminary clinical results. J Thorac Cardiovasc Surg. 1993;106:1111-7.

15. McKenna Jr RJ. Lobectomy by video-assisted thoracic surgery with mediastinal node sampling for lung cancer. J Thorac Cardiovasc Surg. 1994;107:879-82.

16. Yim AP, Landreneau RJ, Izzat MB, et al. Is video-assisted thoracoscopic lobectomy a unified approach? Ann Thorac Surg. 1998; $66: 1155-8$.

17. • Swanson SJ, Herndon JE 2nd, D'Amico TA, et al.: Video-assisted thoracic surgery lobectomy: report of CALGB 39802-a prospective, multi-institution feasibility study. J Clin Oncol 2007;25:4993-7. This study established the feasibility of VATS lobectomy.

18. Ettinger DS, Akerley W, Bepler G, et al. Non, ÄiSmall Cell Lung Cancer. Journal of the National Comprehensive Cancer Network. 2010;8:740-801.

19. Whitson BA, Andrade RS, Boettcher A, et al. Video-assisted thoracoscopic surgery is more favorable than thoracotomy for resection of clinical stage I non-small cell lung cancer. Ann Thorac Surg. 2007;83:1965-70.

20. Cattaneo SM, Park BJ, Wilton AS, et al. Use of video-assisted thoracic surgery for lobectomy in the elderly results in fewer complications. Ann Thorac Surg. 2008;85:231-5. discussion 5-6.

21. Demmy TL, Plante AJ, Nwogu CE, et al. Discharge independence with minimally invasive lobectomy. Am J Surg. 2004;188:698702 .

22. Shaw JP, Dembitzer FR, Wisnivesky JP, et al. Video-Assisted Thoracoscopic Lobectomy: State of the Art and Future Directions. Ann Thorac Surg. 2008;85:S705-9.

23. McKenna R, McVay C: VATS lobectomy in octogenarians. Lung Cancer 2005;49:S356-S.

24. Kaseda S, Aoki T, Hangai N, et al. Better pulmonary function and prognosis with video-assisted thoracic surgery than with thoracotomy. Ann Thorac Surg. 2000;70:1644-6.

25. Nagahiro I, Andou A, Aoe M, et al. Pulmonary function, postoperative pain, and serum cytokine level after lobectomy: a comparison of VATS and conventional procedure. Ann Thorac Surg. 2001;72:362-5.

26. Nomori H, Ohtsuka T, Horio H, et al. Difference in the impairment of vital capacity and 6-minute walking after a lobectomy performed by thoracoscopic surgery, an anterior limited thoracotomy, an anteroaxillary thoracotomy, and a posterolateral thoracotomy. Surg Today. 2003;33:7-12.

27. Nomori $\mathrm{H}$, Horio $\mathrm{H}$, Naruke $\mathrm{T}$, et al. What is the advantage of a thoracoscopic lobectomy over a limited thoracotomy procedure for lung cancer surgery? Ann Thorac Surg. 2001;72:879-84.

28. Nakata M, Saeki H, Yokoyama N, et al. Pulmonary function after lobectomy: video-assisted thoracic surgery versus thoracotomy. Ann Thorac Surg. 2000;70:938-41.

29. Petersen RP, Pham D, Burfeind WR, et al. Thoracoscopic lobectomy facilitates the delivery of chemotherapy after resection for lung cancer. Ann Thorac Surg. 2007;83:1245-9. discussion 50

30. Sugi K, Kaneda Y, Esato K. Video-assisted Thoracoscopic Lobectomy Achieves a Satisfactory Long-term Prognosis in Patients with Clinical Stage IA Lung Cancer. World J Surg. 2000;24:2731.

31. •- Yan TD, Black D, Bannon PG, et al.: Systematic review and meta-analysis of randomized and nonrandomized trials on safety and efficacy of video-assisted thoracic surgery lobectomy for early-stage non-small-cell lung cancer. Journal of clinical oncology: official journal of the American Society of Clinical 
Oncology 2009;27:2553-62. In-depth meta-analysis of the major trials of VATS lobectomy.

32. Sagawa M, Sato M, Sakurada A, et al. A prospective trial of systematic nodal dissection for lung cancer by video-assisted thoracic surgery: can it be perfect? Ann Thorac Surg. 2002;73:900-4.

33. Allen MS, Darling GE, Pechet TTV, et al. Morbidity and Mortality of Major Pulmonary Resections in Patients With Early-Stage Lung Cancer: Initial Results of the Randomized, Prospective ACOSOG Z0030 Trial. Ann Thorac Surg. 2006;81:1013-20.

34. Kirby TJ, Mack MJ, Landreneau RJ, et al. Lobectomy-videoassisted thoracic surgery versus muscle-sparing thoracotomy: A randomized trial. J Thorac Cardiovasc Surg. 1995;109:9971002.

35. Watanabe A, Koyanagi T, Ohsawa H, et al. Systematic node dissection by VATS is not inferior to that through an open thoracotomy: A comparative clinicopathologic retrospective study. Surgery. 2005; 138:510-7.

36. D'Amico TA, Niland J, Mamet R, et al. Efficacy of mediastinal lymph node dissection during lobectomy for lung cancer by thoracoscopy and thoracotomy. Ann Thorac Surg. 2011;92:226-31. discussion 31-2.

37. Passlick B, Kubuschock B, Sienel W, et al. Mediastinal lymphadenectomy in non-small cell lung cancer: effectiveness in patients with or without nodal micrometastases - results of a preliminary study. European Journal of Cardio-Thoracic Surgery. 2002;21:520-6.

38. • McKenna Jr. RJ, Houck W, Fuller CB: Video-Assisted Thoracic Surgery Lobectomy: Experience With 1,100 Cases. Ann Thorac Surg 2006;81:421-6. Largest series of VATS lobectomy by a center of excellence. Illustrates the results that can be obtained by experienced surgeons.

39. Scott WJ, Allen MS, Darling G, et al. Video-assisted thoracic surgery versus open lobectomy for lung cancer: a secondary analysis of data from the American College of Surgeons Oncology Group Z0030 randomized clinical trial. J Thorac Cardiovasc Surg. 2010;139:976-81. discussion 81-3.

40. Damhuis RAM, Schütte PR. Resection rates and postoperative mortality in 7,899 patients with lung cancer. Eur Respir J. 1996;9:7-10.

41. Sugiura H, Morikawa T, Kaji M, et al. Long-term benefits for the quality of life after video-assisted thoracoscopic lobectomy in patients with lung cancer. Surg Laparosc Endosc Percutan Tech. 1999;9:403-8

42. Tajiri M, Maehara T, Nakayama H, et al. Decreased invasiveness via two methods of thoracoscopic lobectomy for lung cancer, compared with open thoracotomy. Respirology. 2007;12:207-11.

43. Muraoka M, Oka T, Akamine S, et al. Video-assisted thoracic surgery lobectomy reduces the morbidity after surgery for stage I non-small cell lung cancer. Jpn J Thorac Cardiovasc Surg. 2006;54:49-55.

44. Petersen RH, Hansen HJ. Learning thoracoscopic lobectomy. European Journal of Cardio-Thoracic Surgery. 2010;37:516-20.

45. Giudicelli R, Thomas P, Lonjon T, et al. Video-assisted minithoracotomy versus muscle-sparing thoracotomy for performing lobectomy. Ann Thorac Surg. 1994;58:712-7. discussion 7-8.

46. Koizumi K, Haraguchi S, Hirata T, et al. Video-assisted lobectomy in elderly lung cancer patients. Jpn J Thorac Cardiovasc Surg. 2002;50:15-22.

47. Shigemura N, Akashi A, Funaki S, et al. Long-term outcomes after a variety of video-assisted thoracoscopic lobectomy approaches for clinical stage IA lung cancer: a multi-institutional study. J Thorac Cardiovasc Surg. 2006;132:507-12.

48. Park BJ, Zhang H, Rusch VW, et al. Video-assisted thoracic surgery does not reduce the incidence of postoperative atrial fibrillation after pulmonary lobectomy. J Thorac Cardiovasc Surg. 2007:133:775-9.

49. Okereke I, Murthy SC, Alster JM, et al. Characterization and importance of air leak after Lobectomy. Ann Thorac Surg. 2005;79:1167-73.

50. Stolz AJ, Schtzner J, Lischke R, et al. Predictors of prolonged air leak following pulmonary lobectomy. European Journal of CardioThoracic Surgery. 2005;27:334-6.

51. Brunelli A, Cassivi SD, Halgren L. Risk factors for prolonged air leak after pulmonary resection. Thorac Surg Clin. 2010;20:359 64.

52. Inada K, Shirakusa T, Yoshinaga Y, et al. The role of video-assisted thoracic surgery for the treatment of lung cancer: lung lobectomy by thoracoscopy versus the standard thoracotomy approach. Int Surg. 2000;85:6-12.

53. Yim AP, Wan S, Lee TW, et al. VATS lobectomy reduces cytokine responses compared with conventional surgery. Ann Thorac Surg. 2000;70:243-7.

54. Shiraishi T, Shirakusa T, Hiratsuka M, et al. Video-assisted thoracoscopic surgery lobectomy for c-T1N0M0 primary lung cancer: its impact on locoregional control. Ann Thorac Surg. 2006;82:1021-6.

55. Grogan EL, Jones DR. VATS lobectomy is better than open thoracotomy: what is the evidence for short-term outcomes? Thorac Surg Clin. 2008;18:249-58.

56. Demmy TL, Curtis JJ. Minimally invasive lobectomy directed toward frail and high-risk patients: a case-control study. Ann Thorac Surg. 1999;68:194-200.

57. Balduyck B, Hendriks J, Lauwers P, et al. Quality of life evolution after lung cancer surgery: A prospective study in 100 patients. Lung Cancer. 2007;56:423-31.

58. Li WWL, Lee TW, Lam SSY, et al. Quality of life following lung cancer resection*. Chest. 2002;122:584-9.

59. McKenna Jr RJ. Complications and learning curves for video-assisted thoracic surgery Lobectomy. Thorac Surg Clin. 2008;18:275-80.

60. Ferguson J, Walker W. Developing a VATS lobectomy programme-can VATS lobectomy be taught? Eur J Cardiothorac Surg. 2006;29:806-9.

61. Sugi K, Sudoh M, Matsuda E, et al. Intrathoracic bleeding during video-assisted thoracoscopic lobectomy and segementectomy. Kyobu Geka. 2003;56:928-31.

62. Whitson BA, D'Cunha J, Andrade RS, et al. Thoracoscopic versus thoracotomy approaches to lobectomy: Differential impairment of cellular immunity. Ann Thorac Surg. 2008;86:1735-44.

63. Craig SR, Leaver HA, Yap PL, et al. Acute phase responses following minimal access and conventional thoracic surgery. Eur J Cardiothorac Surg. 2001;20:455-63.

64. Leaver HA, Craig SR, Yap PL, et al. Lymphocyte responses following open and minimally invasive thoracic surgery. Eur $\mathrm{J}$ Clin Investig. 2000;30:230-8.

65. Craig SR, Leaver HA, Yap PL, et al. Acute phase responses following minimal access and conventional thoracic surgery. European Journal of Cardio-Thoracic Surgery. 2001;20:455-63.

66. Yendamuri S, Nwogu CE, Demmy TL. Thoracoscopic Lobectomy with chest wall resection after neoadjuvant therapy. Innovations: Technology and Techniques in Cardiothoracic and Vascular Surgery. 2009;4:36-8.

67. Yildizeli B, Fadel E, Mussot S, et al. Morbidity, mortality, and long-term survival after sleeve lobectomy for non-small cell lung cancer. Eur J Cardiothorac Surg. 2007;31:95-102.

68. Nakanishi K. Video-assisted thoracic surgery lobectomy with bronchoplasty for lung cancer: initial experience and techniques. Ann Thorac Surg. 2007;84:191-5.

69. Atkins BZ, Harpole Jr DH, Mangum JH, et al. Pulmonary segmentectomy by thoracotomy or thoracoscopy: reduced hospital 
length of stay with a minimally-invasive approach. Ann Thorac Surg. 2007;84:1107-12. discussion 12-3.

70. Nwogu CE, Glinianski M, Demmy TL. Minimally invasive pneumonectomy. Ann Thorac Surg. 2006;82:e3-4.

71. Giulianotti PC, Buchs NC, Caravaglios G, et al. Robot-assisted lung resection: outcomes and technical details. Interact Cardiovasc Thorac Surg. 2010;11:388-92.
72. Gharagozloo F, Margolis M, Tempesta B, et al. Robotassisted lobectomy for early-stage lung cancer: Report of 100 consecutive cases. Ann Thorac Surg. 2009;88:3804.

73. Cerfolio RJ, Bryant AS, Minnich DJ. Starting a robotic program in general thoracic surgery: Why, How, and Lessons Learned. Ann Thorac Surg. 2011;91:1729-37. 